\title{
New UV Spectrophotometric Method for the Estimation of Atazanavir Sulfate in Bulk and Pharmaceutical Dosage Form
}

Soundarya K, Hemant Kumar T**, Manjunath SY

Srikrupa Institute of Pharmaceutical Sciences, Velikatta, Siddipet, Telangana-502277, India

DOI: $\underline{10.36347 / \text { sajp.2020.v09i11.002 }}$

| Received: 12.10 .2020 | Accepted: 26.10.2020 | Published: 06.11.2020

*Corresponding author: Hemant Kumar T

\section{Abstract}

A simple, fast and reliable UV spectrophotometric method has been developed for estimation of atazanavir sulphate in bulk and pharmaceutical dosage form. Estimation was carried out at $\lambda_{\max } 249 \mathrm{~nm}$ using $0.1 \mathrm{~N} \mathrm{HCl}$ as solvent. The linearity was observed in the range of $10-90 \mu \mathrm{g} / \mathrm{ml}$ with correlation coefficient (r) 0.999 . The percentage recovery was found to be in range of 99.84-100.18\%. The proposed method was found to be simple, accurate, precise, and reproducible and gave the acceptable recovery of the analyte which could be directly and easily applied to analysis of bulk and pharmaceutical tablet dosage form of atazanavir sulphate.

Keywords: Atazanavir sulphate; UV spectrophotometry; Tablet dosage form.

Copyright $(\mathcal{2 0 2 0}$ The Author(s): This is an open-access article distributed under the terms of the Creative Commons Attribution 4.0 International License (CC BY-NC 4.0) which permits unrestricted use, distribution, and reproduction in any medium for non-commercial use provided the original author and source are credited.

\section{INTRODUTION}

Atazanavir sulphate (ATV) is a chemically (3S,8S,9S,12S)-3,12-Bis(1,1-dimethylethyl)-8-hydroxy4,11-dioxo-9-(phenylmethyl)-6-\{[4-(2 pyridinyl)phenyl ]methyl $-2,5,6,10,1$ penta aza tetra decane dioic acid dimethyl ester, sulphate (1:1) (Figure-1). ATV is an antiretroviral agent for the treatment of HIV infection and consequently it is clinically useful in the treatment of AIDS [1]. Atazanavir sulfate, azapeptide inhibitor of HIV-1 protease, is indicated in combination with other antiretroviral agents for the treatment of HIV-1 infection [2]. Atazanavir sulfate is a white to pale yellow powder. It is slightly soluble in water [2]. The drug was approved by the United States Food and Drug Administration (USFDA) in June 2003. Structureactivity studies with a series of azadipeptides designed to mimic the transition state of the peptide-cleavage reaction catalyzed by HIV-1 protease identified lead compounds that had either potent antiviral activity against mutant HIV-1 strains or good oral bioavailability, but not both. Atazanavir is given with food by mouth as the sulfate and the usual adult dose is $400 \mathrm{mg}$ once daily [3]. The drug is well absorbed when administered orally with food (bioavailability 68\%). The drug is highly bound to plasma proteins $(86 \%)$ and is metabolized by CYP3A isozyme. It is a moderate inhibitor of CYP3A.Literature survey revealed few spectrophotometric methods [4-6], RP-HPLC methods [7-13] and HPTLC methods [14] available for estimation of Atazanavir sulfate in bulk and pharmaceutical formulation.

Here attempt is made to develop simple UV spectrophotometric method for estimation of atazanavir sulfate in bulk and formulation with good accuracy, simplicity, precision and economy over other chromatographic methods and which can be used for routine analysis. The method was validate as per ICH guidelines [15].<smiles>COC(=O)N[C@H](C(=O)N[C@@H](Cc1ccccc1)[C@@H](O)CN(Cc1ccc(-c2ccccn2)cc1)NC(=O)[C@@H](NC(=O)OC)C(C)(C)C)C(C)(C)C</smiles>

Fig-1: Structure of atazanavir sulfate

\section{MATERIALS \& METHODS \\ Instrumentation}

An ELICO UV/Visible spectrophotometer model SL 244 with $10 \mathrm{~mm}$ matched quartz cells was 
used for all spectral measurements. An electronic digital weighing balance (1 mg sensitivity, SHIMADZU AUX 220) used for weighing purpose.

\section{Chemicals and Reagents}

All reagents and chemicals used were of Analytical Grade. Gift sample of atazanavir sulfate was supplied by Vivid labs, Hyd. Marketed formulation Atazor capsules (label claim $300 \mathrm{mg}$ ) was procured from local market

\section{Preparation of standard stock solution}

Accurately weighed $10 \mathrm{mg}$ of atazanavir sulfate was transferred into $100 \mathrm{ml}$ volumetric flask and the content was dissolved in $0.1 \mathrm{~N} \mathrm{HCl}$ and volume was made up to the mark with $0.1 \mathrm{~N} \mathrm{HCl}$ to get a stock solution containing $100 \mu \mathrm{g} / \mathrm{ml}$.

\section{Preparation of working standard solution}

From the standard stock solution $5 \mathrm{ml}$ was transferred to $10 \mathrm{ml}$ volumetric flask and diluting to 10 $\mathrm{ml}$ with $0.1 \mathrm{~N} \mathrm{HCl}$ to get a concentration of $50 \mu \mathrm{g} / \mathrm{ml}$. Working standard solution of atazanavir sulfate was scanned between 200-400 $\mathrm{nm}$. The wavelength maximum exhibited for atazanavir sulfate was at 249 nm (Fig-2).

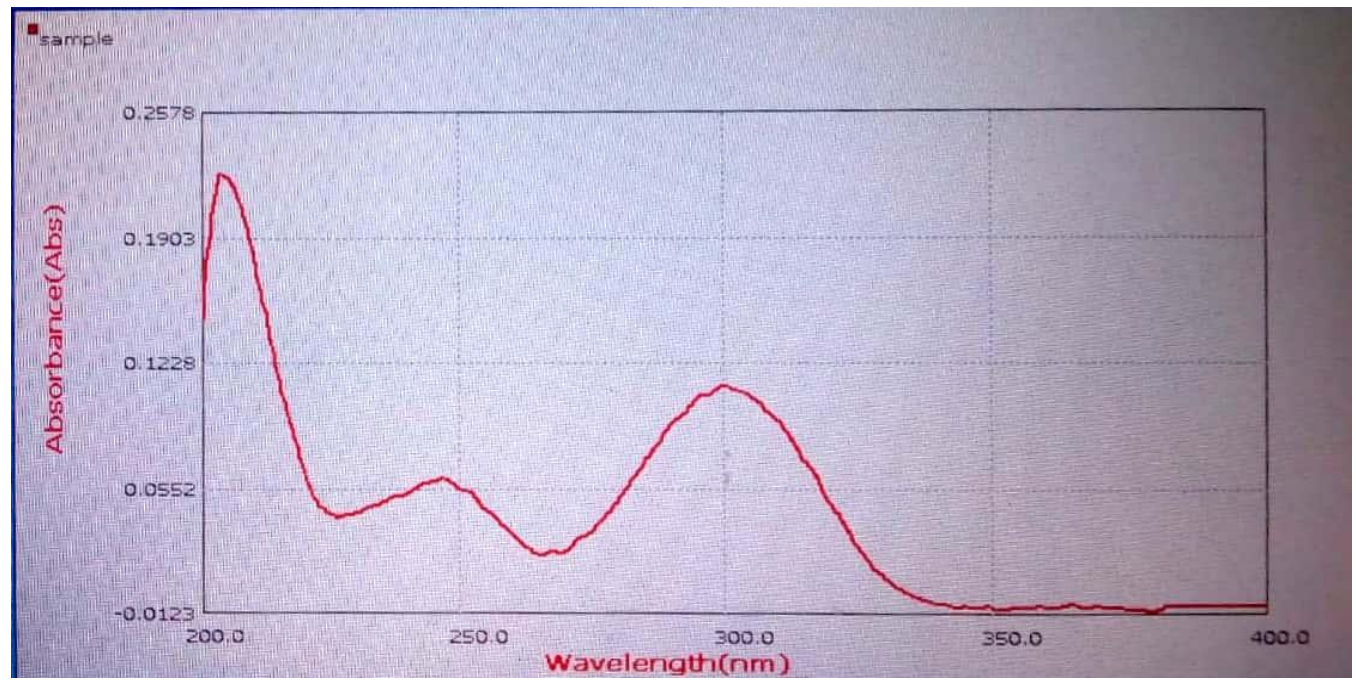

Fig-2: UV spectra of atazanavir sulfate

\section{Procedure for Calibration Curve}

Appropriate volume of aliquot (1-9 ml) from standard stock solution was transferred to volumetric flask of $10 \mathrm{ml}$ capacity. The volume was adjusted to the mark with $0.1 \mathrm{~N} \mathrm{HCl}$ to give solutions concentrations in the range of $10-90 \mu \mathrm{g} / \mathrm{ml}$. The absorbance measurements of these solutions were carried out against $0.1 \mathrm{~N} \mathrm{HCl}$ as blank at $249 \mathrm{~nm}$. Calibration curve was constructed by plotting absorbance versus concentrations. Linear regression equation was obtained from this calibration curve.

\section{Procedure for Pharmaceutical Formulation}

Ten capsules (ATAZOR) were weighed and average weight was calculated. Capsule content powder equivalent to $10 \mathrm{mg}$ atazanavir sulfate was accurately weighed and transferred to $100 \mathrm{ml}$ volumetric flask. To this $60 \mathrm{ml}$ of $0.1 \mathrm{~N} \mathrm{HCl}$ was added and sonicated for 10 min. The flask was shaken and volume was made up to the mark with $0.1 \mathrm{~N} \mathrm{HCl}$. The above solution was filtered through whatmann filter paper No.41. From the above solution $5 \mathrm{ml}$ was transferred to $10 \mathrm{ml}$ volumetric flask. Volume was made up to the mark with $0.1 \mathrm{~N} \mathrm{HCl}$ to give a solution containing $50 \mu \mathrm{g} / \mathrm{ml}$. The content in the capsule was calculated from the calibration curve.

\section{RESULTS AND DISCUSSION Method Validation}

The developed method was validated in terms of Linearity, precision, accuracy, Limit of detection (LOD) and Limit of Quantitation (LOQ), robustness and ruggedness.

\section{Linearity}

Nine points calibration curve were obtained in a concentration range from $10-90 \mu \mathrm{g} / \mathrm{ml}$ for atazanavir sulfate. The response of the drug was found to be linear in the investigation concentration range and the linear regression equation was $\mathrm{y}=0.0103 \mathrm{x}+0.0076$ with correlation coefficient 0.999 (Table 1 and 2, Fig-2). 


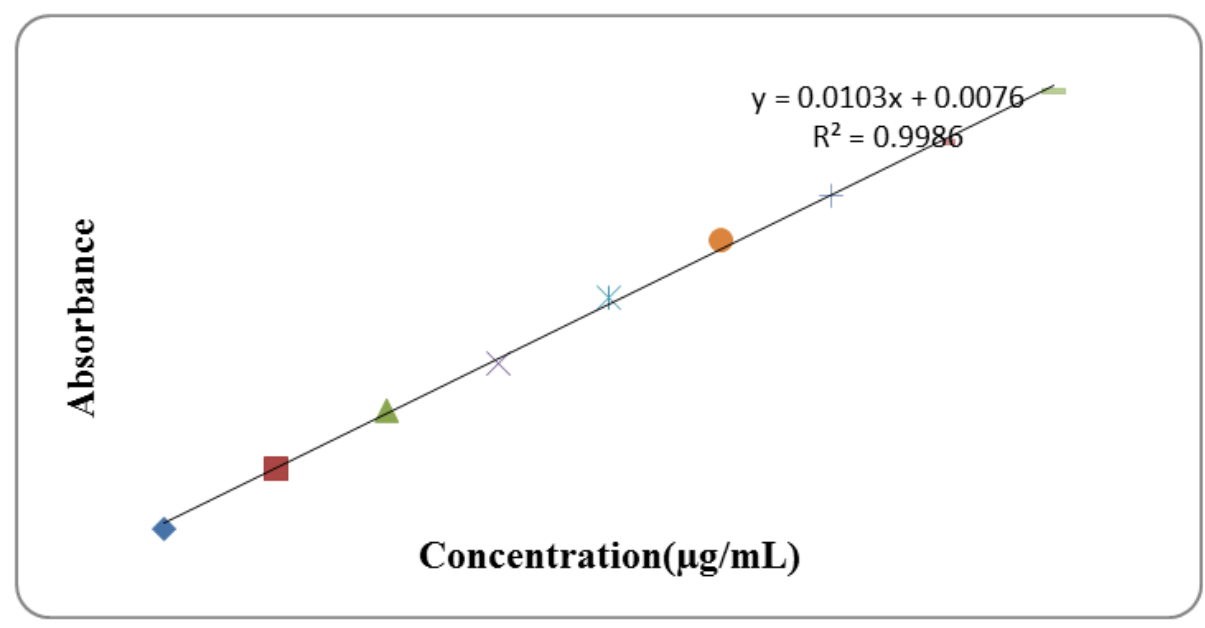

Table-1: Linearity Data for Atazanavir sulfate

\begin{tabular}{|l|l|l|}
\hline S. NO & Concentration $(\boldsymbol{\mu g} / \mathbf{m l})$ & Absorbance \\
\hline 1 & 10 & 0.1001 \\
\hline 2 & 20 & 0.2131 \\
\hline 3 & 30 & 0.3234 \\
\hline 4 & 40 & 0.4128 \\
\hline 5 & 50 & 0.5376 \\
\hline 6 & 60 & 0.6458 \\
\hline 7 & 70 & 0.7300 \\
\hline 8 & 80 & 0.8305 \\
\hline 9 & 90 & 0.9259 \\
\hline
\end{tabular}

Table-2: Optical Characteristics of atazanavir sulfate

\begin{tabular}{|l|l|l|}
\hline S. No & Parameters & Method \\
\hline 1. & $\lambda$ max $(\mathrm{nm})$ & 249 \\
\hline 2. & Beers law limit $(\mu \mathrm{g} / \mathrm{ml})$ & $10-90$ \\
\hline 3. & Sandell's sensitivity $\left(\mu \mathrm{g} / \mathrm{cm}^{2} / 0.001\right.$ A.U $)$ & 0.0102 \\
\hline 4. & Molar absorptivity $\left(\mathrm{L} \mathrm{mol}^{-1} \mathrm{~cm}^{-1}\right)$ & $7.89 \times 10^{3}$ \\
\hline 5. & Correlation coefficient $(\mathrm{r})$ & 0.9986 \\
\hline 6. & Regression equation $(\mathrm{Y}=\mathrm{mX}+\mathrm{c})$ & $\mathrm{Y}=0.0103 \mathrm{X}+0.076$ \\
\hline 7. & Slope $(\mathrm{m})$ & 0.0103 \\
\hline 8. & Intercept $(\mathrm{c})$ & 0.0076 \\
\hline 9. & LOD $(\mu \mathrm{g} / \mathrm{ml})$ & 0.21 \\
\hline 10. & LOQ $(\mu \mathrm{g} / \mathrm{ml})$ & 0.65 \\
\hline 11. & Standard error of mean of Regression line & 0.00494 \\
\hline
\end{tabular}

\section{Precision}

Precision was checked in terms of repeatability, inter and intraday precision. It was expressed in percentage RSD.

\section{Repeatability}

The repeatability was evaluated by assaying six times of sample solution prepared for assay determination. Percentage RSD was calculated (Table$3)$.
Table-3: Repeatability

\begin{tabular}{|l|l|}
\hline Concentration $(\boldsymbol{\mu g} / \mathbf{m l})$ & Absorbance \\
\hline 50 & 0.5350 \\
\hline 50 & 0.5352 \\
\hline 50 & 0.5350 \\
\hline 50 & 0.5394 \\
\hline 50 & 0.5306 \\
\hline 50 & 0.5352 \\
\hline Mean & 0.5350 \\
\hline Standard Deviation & 0.0027 \\
\hline$\%$ RSD & 0.50 \\
\hline
\end{tabular}




\section{Interday and Intraday precision}

The intraday and interday precision study of atazanavir sulfate was carried out by estimating different concentrations of atazanavir sulfate three times on the same day (intraday precision) and on three different days (interday precision) and the results were reported in terms of Percentage RSD (Table-4).

Table-4: Interday \& Intraday Precision

\begin{tabular}{|l|l|l|l|l|l|}
\hline \multirow{2}{*}{ S. No } & \multirow{2}{*}{ Concentration $(\boldsymbol{\mu g} / \mathbf{m l})$} & \multicolumn{2}{|l|}{ Interday } & \multicolumn{2}{l|}{ Intraday } \\
\cline { 3 - 6 } & & SD & \%RSD & SD & \%RSD \\
\hline 1 & 40 & 0.00057 & 1.07 & 0.001 & 1.72 \\
\hline 2 & 50 & 0.0025 & 1.63 & 0.0015 & 0.98 \\
\hline 3 & 60 & 0.003 & 1.17 & 0.0026 & 1.03 \\
\hline
\end{tabular}

\section{Accuracy}

Accuracy was assessed by determination of the recovery of the method by addition of standard drug to the known amount of marketed formulation at three different concentration levels 80,100 and $120 \%$ taking into consideration percentage purity of added bulk drug samples. Each concentration was analyzed three times and average recoveries were measured (Table-5).

Table-5: Accuracy Studies

\begin{tabular}{|l|l|l|l|l|}
\hline Name of Drug & Spiked Level & Conc. Added $(\boldsymbol{\mu g} / \mathbf{m l})$ & Conc. Recovered $(\boldsymbol{\mu g} / \mathbf{m l})$ & $\boldsymbol{\%}_{\text {Recovery } \pm \text { SD }}$ \\
\hline \multirow{3}{*}{ Atazanavir Sulfate } & $80 \%$ & 40 & 40.07 & $100.18 \% \pm 0.0256$ \\
\cline { 2 - 5 } & $100 \%$ & 50 & 49.92 & $99.84 \% \pm 0.0582$ \\
\cline { 2 - 5 } & $120 \%$ & 60 & 59.97 & $99.95 \% \pm 0.0421$ \\
\hline
\end{tabular}

*Average of three determinations

\section{Robustness}

The robustness of a method is its capacity to remain unaffected by small changes in conditions. To determine the robustness of the method, the experimental conditions were deliberately altered and assay was evaluated. The effect of detection wavelength was studied at $\pm 2 \mathrm{~nm}$. The effect of temperature was studied at $\pm 2{ }^{\circ} \mathrm{C}$. The effect of solvent strength at \pm
$0.02 \mathrm{~N} \mathrm{HCl}$ concentration.For changes of conditions, the sample was assayed in triplicates. When the effect of altering one set of conditions was tested, the other conditions were held constant at the optimum values. Assay for all deliberate changes of conditions should be within 98.0-102.0\% for the proposed method (Table$6)$.

Table-6: Robustness results

\begin{tabular}{|l|l|l|l|l|l|l|l|}
\hline \multirow{2}{*}{ S.No } & \multirow{2}{*}{ Concentration $(\boldsymbol{\mu g} / \mathbf{m l})$} & \multicolumn{2}{l|}{ wavelength } & \multicolumn{2}{l|}{ Temperature $\left({ }^{\mathbf{0}}\right)$} & \multicolumn{2}{l|}{ Concentration } \\
\cline { 3 - 8 } & & $\mathbf{2 4 7} \mathbf{~} \mathbf{m}$ & $\mathbf{2 5 1} \mathbf{~ n m}$ & $\mathbf{2 6}$ & $\mathbf{3 0}$ & $\mathbf{0 . 0 8} \mathbf{H C l}$ & $\mathbf{0 . 1 2 N} \mathbf{H C l}$ \\
\hline 1 & 50 & 0.532 & 0.532 & 0.537 & 0.547 & 0.547 & 0.543 \\
\hline 2 & 50 & 0.533 & 0.532 & 0.532 & 0.540 & 0.547 & 0.540 \\
\hline 3 & 50 & 0.534 & 0.532 & 0.523 & 0.542 & 0.547 & 0.542 \\
\hline 4 & 50 & 0.530 & 0.532 & 0.533 & 0.540 & 0.549 & 0.543 \\
\hline 5 & 50 & 0.532 & 0.532 & 0.530 & 0.547 & 0.547 & 0.524 \\
\hline 6 & 50 & 0.537 & 0.523 & 0.532 & 0.545 & 0.547 & 0.540 \\
\hline AVG & 0.532 & 0.530 & 0.531 & 0.543 & 0.547 & 0.538 \\
\hline SD & 0.001 & 0.003 & 0.004 & 0.003 & 0.0009 & 0.007 \\
\hline \%RSD & 0.2 & 0.7 & 0.8 & 0.5 & 0.1 & 1.3 \\
\hline
\end{tabular}

\section{Ruggedness}

Ruggedness of the proposed method is determined by analysis of aliquots from homogeneous slot by two analysts using same operational and environmental conditions (Table-7).

Table-7: Ruggedness Studies

\begin{tabular}{|l|l|l|l|}
\hline Formulation & Amount of drug taken from tablet(mg) & Analyst 1 & Analyst 2 \\
\cline { 3 - 4 } & & $(\mathbf{n}=3) \%$ Assay $\pm \%$ RSD & $(\mathbf{n}=3) \%$ Assay $\pm \%$ RSD \\
\hline Atazor(capsules) & 300 & $99.83 \pm 0.243$ & $99.86 \pm 0.324$ \\
\hline
\end{tabular}

Limit of Detection (LOD) and Limit of Quantitation (LOQ)

The LOD and LOQ were calculated according to below equation given by
$\mathrm{LOD}=3.3 \mathrm{\sigma} / \mathrm{s}$

$\mathrm{LOQ}=10 \mathrm{\sigma} / \mathrm{s}$ 
Where $\sigma$ is the standard deviation of $y$ intercepts of regression lines and $\mathrm{s}$ is the slope of the calibration curve (Table-2).
Application of method to formulation

The proposed was applied to pharmaceutical formulation of atazanavir sulfate (Table-8).

Table-8: Assay

\begin{tabular}{|l|l|l|l|}
\hline Formulation & Labeled Amount(mg) & Amount* Obtained(mg) & \%Purity \pm SD \\
\hline Atazor (Capsules) & 300 & 299.86 & $99.86 \% \pm 0.685$ \\
\hline
\end{tabular}

*Average of three determinations

\section{CONCLUSION}

The method proposed in the above study was found to be simple, specific, economic, precise and rapid for the determination of Atazanavir sulfate in bulk as well as in its dosage form. Sample recoveries in all formulations were in good agreement with their respective label claims without interference of excipients and additives. Being economic and precise, the developed method may be preferred as an alternative method for the routine analysis of the Atazanavir sulfate in bulk and pharmaceutical dosage form.

\section{ACKNOWLEDGMENTS}

Authors are also thankful to Srikrupa Institute of Pharmaceutical Sciences, Siddipet for providing necessary facilities for the research work.

\section{REFERENCES}

1. Raja A, Lebbos J, Kirkpatrick P. Atazanavir sulphate, Nat. Rev. Drug Discov. 2003;2: 857858.

2. Fässler A, Bold G, Capraro HG. Aza-peptide analogues as potent human immunodeficiency virus type-1 protease inhibitors with oral bioavailability. J. Med.Chem. 1996;39:32033216.

3. Bold G, Fässler A, Capraro HG. New azadipeptide analogues as potent and orally absorbed HIV-1 protease inhibitors: candidates for clinical development. J Med Chem. 1998; 41 :3387-3401

4. Khanage SG, Deshmukh VK, Mohite PB. Development of derivative spectroscopic estimation of atazanavir sulphate in bulk drug and pharmaceutical dosage forms. Int. J. Pharm Health Sci. 2010; 1(3); 149-154.

5. Minal RG, Manoj MK. Development And Validation Of UV Spectrophotometric Methods For Estimation Of Atazanavir Sulphate In Bulk And Tablet Dosage Form. Int J Pharm Pharm Sci. 2014; 6(7), 351-353.

6. Pathi J, Reddy PR, Raju NA. Visible spectrophotometric estimation of atazanavir in pharmaceutical formulations. Research Journal of Pharmacy and Technology. 2011;4(2): 273-275.
7. Bhirud CH. Stability indicating RP-HPLC method for the determination of Atazanavir sulpha in bulk and dosage form. Drug Invention Today. 2013; $5(2): 81-86$.

8. [8]. Chitturi S, Somannavar R, Peruri YS. Gradient RP-HPLC method for the determination of potential impurities in atazanavir sulfate. J. Pharma. Biomed. Anal. 2011; 55: 31-47.

9. Dailly E, Raffi F, Jolliet P. Determination of atazanavir and other antiretroviral drugs plasma levels by high performance liquid chromatography with UV- detection. J. Chromatogr. B. Analyt. Technol. Biomed Life Sci. 2005; 813; 353-358.

10. Srinivasu K, Rao VJ, Raju NA, Mukkanti K. Validated RP-HPLC Method for the Determination of Atazanavir in Pharmaceutical Dosage Form. E-J Chem. 2011; 8(1):453-456.

11. Arianna L, Silvana P, Elisa B, Giologio P, Giuseppe PS. Simple activation of the HIV protease inhibition atazanavir in human plasma by HPLC with UV detection. Journal of Pharmaceutical and Biomedical Analysis. 2006; 42: 500-505.

12. Padmalatha MK. Vanitha Prakash and Eranna Dopadally Validated, reverse phase high performance liquid chromatography method for the estimation of atazanavir sulfate in pharmaceutical formulations. Oriental Journal of Chemistry. 2010; 26(1):123-127.

13. Olivier T, Clemence VM, Cedric A. Simultaneous quantitative assay of atazanavir and six other HIV proteaseinhibitors by isocratic reversed-phase liquid chromatography in human plasma. Therap. Biomed. Drug Monit. 2005; 27;265-269.

14. Gadhvi M, Bhandari A. Simultaneous Determination of Ritonavir and Atazanavir in Combined Tablet Dosage Form by HPTLC. Asian J Biomedical and Pharma Sci. 2011; 2(15):15-19.

15. ICH - Guidelines Q2A, Validation of Analytical Procedures: Definition and Terminology (CPMP III/5626/94) March (1995). Geneva, Switzerland: ICH. ICH - Guidelines Q2B, Validation of Analytical Procedures: Methodology, (CPMP/ICH/281/95) November (1996). Geneva, Switzerland: ICH. 